\title{
Schematic Structure of the Quiet Sun
}

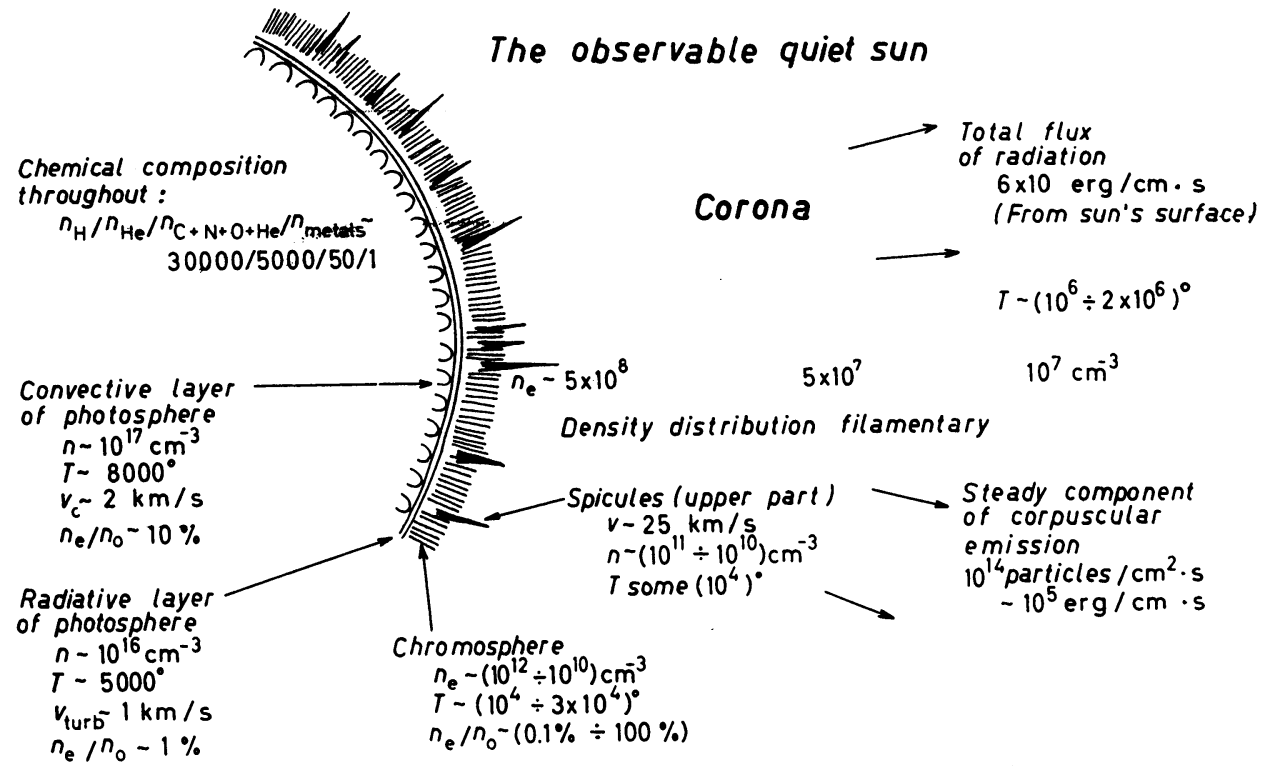

K. O. KIEPENHEUER

\section{Mode 1 of il Aclic Region of the Sun}

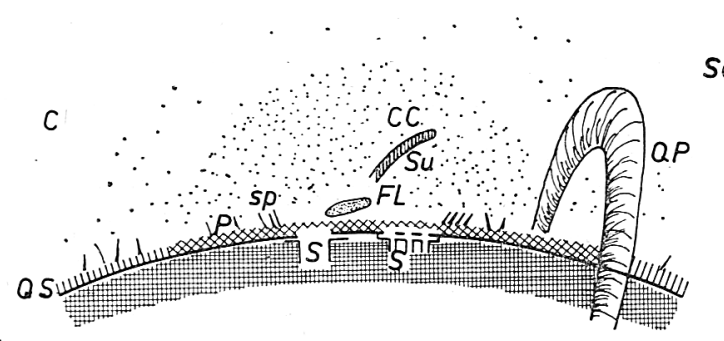

QS $=$ Quiet sun

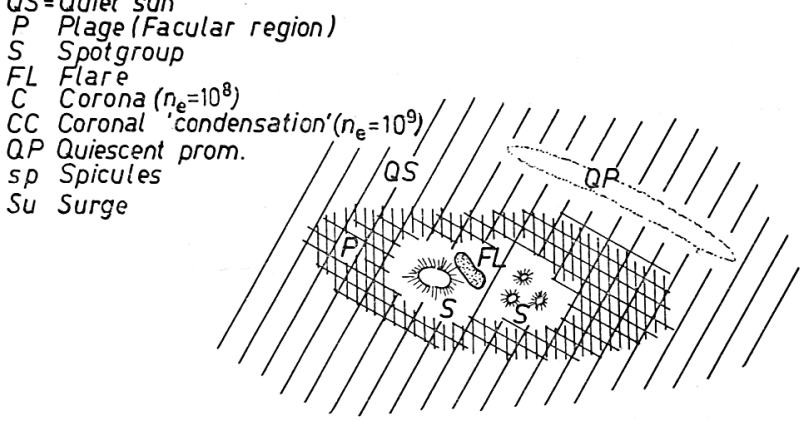

Seen from aside

Seen from above

C. DE JAGER 